\title{
A Light-Independent Magnetic Compass in the Leatherback Sea Turtle
}

\author{
KENNETH J. LOHMANN AND CATHERINE M. FITTINGIOFF LOIIMANN \\ Department of Biology, Coker Hall, CB-3280, University of North Carolina, Chapel Hill, \\ North Carolina 27599
}

\begin{abstract}
Diverse animals can orient to the earth's magnetic field (1-6), but the mechanism or mechanisms underlying magnetic field detection have not been determined. Behavioral (7-9) and neurophysiological (10-12) results suggest that the transduction process underlying magnetic compass orientation in vertebrates is light-dependent, a finding consistent with theoretical models proposing that magnetoreception involves a modulation of the response of retinal photoreceptors to light $(13,14)$. We report, however, that leatherback sea turtle (Dermochelys coriacea) hatchlings orient to the geomagnetic field in complete darkness. Thus, light-dependence is not a universal feature of vertebrate magnetic compasses.
\end{abstract}

Immcdiatcly after emerging from underground nests on oceanic beaches, sea turtle hatchlings enter the sea and swim toward the open ocean in a migration lasting several days. Hatchlings leaving the east coast of Florida quickly establish easterly courses that lead them away from land and toward the Gulf Stream current (15-17). Previous laboratory experiments have demonstrated that hatchling loggerhead turtles (Caretta caretta) will orient to the earth's magnetic field (2). To determine whether leatherbacks have a similar ability and whether the transduction mechanism underlying magnetic compass orientation in sea turtles is dependent on light, we investigated the orientation of hatchling leatherbacks swimming in darkness.

Hatchling leatherback sea turtles were obtained from nests deposited on beaches in the vicinity of Fort Pierce, Florida. Nests were examined daily. When a depression formed in the sand above a nest (indicating that the eggs had hatched and that emergence would probably occur that night), several hatchlings were removed, placed into a darkened styrofoam cooler, and transported to the lab-

Received 18 February 1993; accepted 27 May 1993. oratory. Orientation was assessed in a circular water-filled arena surrounded by a Rubens cube coil (18) (Fig. 1) that could be used to reverse the direction of the horizontal component of the ambient magnetic field. Experiments were conducted in a light-tight room between sundown and sunrise, the time when most hatchlings normally enter the sea $(19,20)$. To eliminate the light emanating from computers and power supplies, all electronic equipment was removed from the room. As an additional precaution against unexpected light sources (e.g., bioluminescence), an observer periodically sat silently beside the coil while experiments were in progress. Following dark-adaptation of one hour or longer, three different observers were unable to perceive any light in the room despite systematic searches and efforts to elicit bioluminescent flashes by stirring the water.

While in darkness, hatchling leatherbacks tested in the earth's magnetic field were significantly oriented in an eastward direction (Fig. 2a). In contrast, hatchlings tested in darkness under reversed field conditions oriented in approximately the opposite direction (Fig. 2 b). The two distributions are significantly different, indicating that the ambient magnetic field influenced the orientation of hatchling leatherbacks swimming in darkness.

These results demonstrate that leatherbacks are able to detect the geomagnetic field in the absence of visible light. We conclude that the transduction mechanism underlying magnetic compass orientation is not light-dependent in all vertebrate species.

The magnetic compass of sea turtles could rely on a mechanism different from that used by other vertebrates. The functional characteristics of the loggerhead turtle compass and those of magnetic compasses in two other vertebrate classes, however, appear identical. Like the magnetic compass of birds (5) and of shoreward-orienting newts (4), the loggerhead compass is axial and based on 


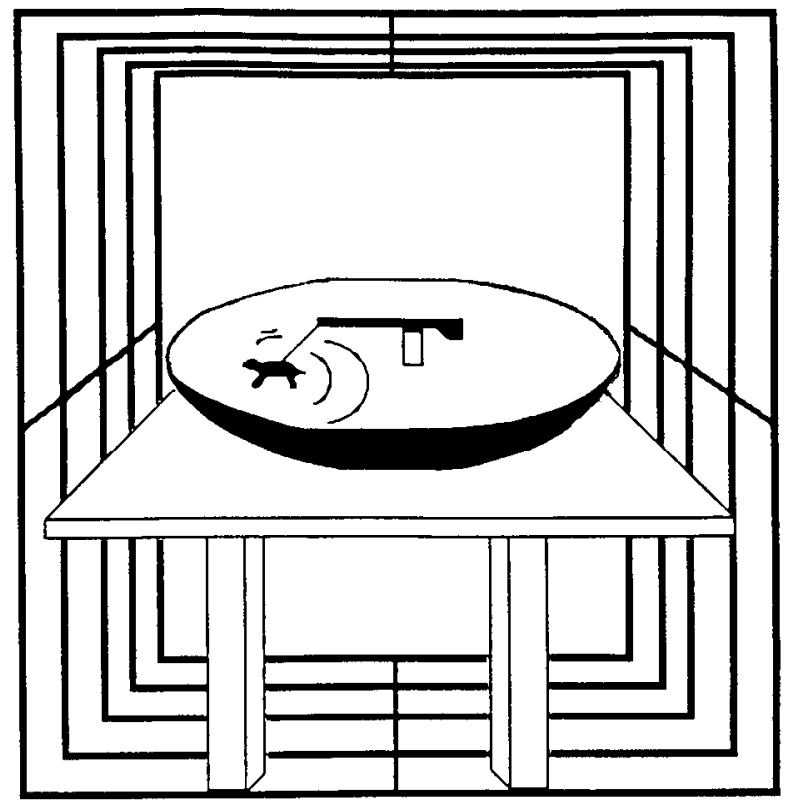

Figure 1. The orientation arena was an inverted fiberglass satellite dish (1.02 $\mathrm{m}$ diameter) filled with water. The arena was surrounded by a Rubens cube coil $130 \mathrm{~cm}$ on a side. Prior to testing, each hatchling was placed into a nylon-Lycra harness that encircled the turtle's carapace without impeding swimming (15). The harness was connected by a short monofilament line to a lever arm mounted on a $360^{\circ}$ rheostat. The rheostat was positioned on a post in the center of the orientation arena (2). The lever arm was free to rotate within the horizontal plane and could easily be pulled clockwise or counterclockwise by a swimming turtle. The arm thus tracked the direction toward which the hatchling swam. The central rheostat was wired to a computer in an adjacent room, which recorded the orientation of the turtle every $30 \mathrm{~s}$ with an accuracy of $\pm 2^{\circ}$. Thus, the orientation of turtles swimming in darkness could be tracked.

Methods: Detailed descriptions of methods are provided in ref \#2. Each hatchling was tested once on either its first, second, or third night of captivity. Each trial began in the earth's field (coil off) with a dim light hanging in magnetic east so that hatchlings quickly established a course toward the light (2). The light was provided because hatchlings emerging from their nests at night under natural conditions find the sea using light cues associated with the ocean surface (25); light reflected from the ocean may also provide a directional cue necessary for hatchlings to initiate a seaward course $(2,26)$. After one hour, the light was turned off and the turtles were permitted to swim in darkness either in the unaltered magnetic field (i.e., the coil remained off) or in a reversed field (i.e., the coil was turned on 10-20 s after the light was turned off). Ten minutes after the light was turned off, the computer began recording the orientation of each hatchling at 30-s intervals. Thus, orientation data were collected only while the turtles were swimming in darkness. Between trials, we periodically altered the position of the power supply relative to the arena to reduce the chance that subtle sounds or vibrations could serve as an orientation cue; such positional changes, however, had no discernible effect on orientation.

field line inclination, rather than on field polarity (21). The possibility therefore exists that all three compasses are based on a common underlying mechanism.

One hypothesis for magnetic field detection in vertebrates proposes that particles of the mineral magnetite transduce geomagnetic stimuli to the nervous system (22). Although magnetite particles have been detected in cephalic tissues of sea turtles (23) and in numerous other animals known to orient magnetically (22), no direct neurophysiological evidence has been obtained demonstrating a link between magnetite and magnetic field detection in any multicellular organism.

A second hypothesis of magnetoreception has been proposed for elasmobranch fishes. Thesc animals possess sensitive electroreceptors that may endow them with a magnetic compass sense based on electromagnetic induction (24). Because electroreceptors have not been found in reptiles, however, an induction-based mechanism appears unlikely for sea turtles. Moreover, the elasmobranch induction hypothesis requires consistent movement through the earth's magnetic field, yet hatchlings successfully oriented magnetically while tethered and nearly stationary (Fig. 1).

A third hypothesis proposes that magnetoreception occurs in photoreceptors through a transduction process requiring light $(7,13,14)$. Our results demonstrate that light is not necessary for magnetic orientation in marine turtles. The results are therefore not consistent with current models of light-dependent magnetoreception. Further research will be required to determine whether the light-independent magnetic compass of sea turtles relies on different

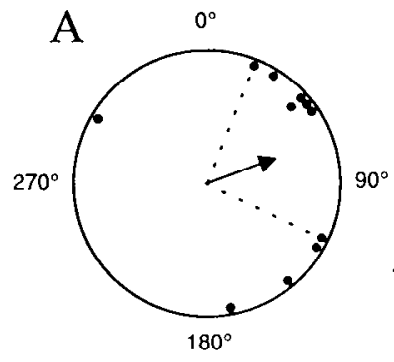

Earth's Magnetic Field

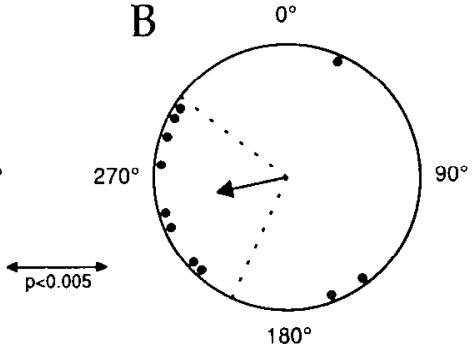

Reversed Field
Figure 2. Results of magnetic orientation experiments with hatchling leatherbacks tested in darkness. (A) Mean angles of hatchlings tested in the earth's magnetic field. The group was significantly oriented with a mean angle of $70^{\circ}$ (Rayleigh test: $r=0.55, Z=3.33, P<0.05$ ). (B) Mean angles of hatchling leatherbacks tested in darkness in a reversed field. The group was significantly oriented with a mean angle of $255^{\circ}$ (Rayleigh test: $\mathrm{r}=0.53, \mathrm{Z}=3.09, P<0.05$ ). The arrow between the two distributions indicates they are significantly different (Watson test: $\left.\mathrm{U}^{2}=0.300, P<0.005\right)$. Arrows in the center of each circle indicate the mean angle of the group; the arrow length is proportional to the magnitude of the mean vector $r$, with the radius of the circle corresponding to $r=1$. Dashed lines indicate the $95 \%$ confidence interval for the mean angle (27).

Methods: Procedures used in analyzing orientation data are described in detail in ref \#2, except that: (i) the accuracy of measurements in this study was improved to $\pm 2^{\circ}$, and (ii) to avoid tiring leatherback hatchlings (an endangered species) before release, we terminated experiments as soon as a turtle completed its first oricnted swimming period; the mean angle of this period (2) was the hatchling's orientation angle. 
receptors than the apparently light-dependent magnetic compasses of birds $(5,9)$ and newts $(7)$, or whether all three compasses in fact share a common underlying mechanism.

\section{Acknowledgments}

We thank Jay Callaway for developing the data acquisition software, Mike Salmon and Jeanette Wyneken for discussions of experimental protocols, and Erik Martin and Robert Ernest for assistance in locating leatherback turtle nests. The work was supported by NSF grants IBN9120338 and BNS-87-07173. Endangered species research was authorized under Florida DNR special permit TP 073.

\section{Literature Cited}

1. Lohmann, K. J., and A. O. D. Willows. 1987. Lunar-modulated geomagnetic orientation by a marine mollusk. 235: 331334

2. Lohmann, K. J. 1991. Magnetic orientation by hatchling loggerhead sea turtles (Caretta caretta). J. Exp. Biol. 155: 37-49.

3. Quinn, T. P. 1980. Evidence for celestial and magnetic compass orientation in lake migrating sockeye salmon fry. J. Comp. Physiol. A. 137: 243-248.

4. Phillips, J. B. 1986. Two magnetoreception pathways in a migratory salamander. Science 233: 765-767.

5. Wiltschko, W., and R. Wiltschko. 1988. Magnetic orientation in birds. Pp. 67-121 in Current Ornithology, vol. 5, Johnston, R. F., ed. Plenum Press, New York.

6. Burda, H., S. Marhold, T. Westenberger, R. Wiltschko, and W. Wiltschko. 1990. Magnetic compass orientation in the subterranean rodent Cryptomys hottentotus. Expertentla 46: 528-530.

7. Phillips, J. B., and S. C. Borland. 1992. Behavioural evidence for use of a light-dependent magnetoreception mechanism by a vertebrate. Nature 359: 142-144.

8. Phillips, J. B., and S. C. Borland. 1992. Wavelength specific effects of light on magnetic compass orientation of the eastern red-spotted newt Notophthalmus viridescens. Ethol. Ecol. Evol. 4: 33-42.

9. Wiltschko, W., and R. Wiltschko. 1981. Disorientation of inexperienced young pigeons after transportation in total darkness. Nature 291: 433-434.

10. Olcese, J., S. Reuss, and P. Semm. 1988. Geomagnetic field detection in rodents. Life Sci. 42: 605-613.

11. Semm, P., D. Nohr, C. Demaine, and W. Wiltschko. 1984. Neural basis of the magnetic compass: interactions of visual, magnetic and vestibular inputs in the pigeon's brain. J. Comp. Physiol. A. 155: 283-288.

12. Semm, P., and C. Demaine. 1986. Neurophysiological properties of magnetic cells in the pigeon's visual system. J. Comp. Physiol. A. 159: 619-625.

13. Leask, M.J. M. 1977. A physicochemical mechanism for magnetic field detection by migrating birds and homing pigeons. Nature 267 : 141-145.

14. Schulten, K., and A. Windemuth. 1986. Model for a physiological magnetic compass. Pp. 99-106 in Biophysical Effects of Steady Magnetic Fields, G. Maret, N. Boccara, and J. Kiepenheuer, eds. Springer-Verlag, Berlin.

15. Salmon, M., and J. Wyneken. 1987. Orientation and swimming behavior of hatchling loggerhead turtles (Caretta caretta L.) during their offshore migration. J. Exp. Mar. Biol. Ecol. 109: 137-153.

16. Carr, A. 1986. Rips, FADS, and little loggerheads. BioScience 36: 92-100.

17. Carr, A. 1986. New perspectives on the pelagic stage of sed turtle development. NOAA Tech. Memorandum NMFS-SEFC 190: 1-36.

18. Rubens, S. M. 1945. Cube-surface coil for producing a uniform magnetic field. Rev. Sci. Instrum. 16: 243-245.

19. Witherington, B. E., K. A. Bjorndal, and C. M. McCabe. 1990. Temporal pattern of nocturnal emergence of loggerhead turtle hatchlings from natural nests. Copeia 4: 1165-1168.

20. Bustard, H. R. 1967. Mechanism of nocturnal emergence from the nest in green turtle hatchlings. Nature 214: 317-318.

21. Light, P., M. Salmon, and K. J. Lohmann. 1993. Geomagnetic orientation of loggerhead sea turtles: evidence for an inclination Compass. J. Exp. Biol. (in press).

22. Kirschvink, J. I., D. S. Jones, and B. J. MacFadden. 1985. Magnetite Biomineralization and Magnetoreception in Organisms. Plenum Press, New York.

23. Perry, A., G. B. Bauer, and A. E. Dizon. 1985. Magnetoreception and biomineralization of magnetite in amphibians and reptiles. Pp. 439-453 in Magnetite Biomineralization and Magnetoreception in Organisms, J. L. Kirschvink, D. S. Jones and B. J. MacFadden, eds. Plenum Press, New York.

24. Kalmijn, A. J. 1978. Experimental evidence of geomagnetic orientation in elasmobranch fishes. Pp. 347-353 in Animal Migration, Orientation, and Homing. K. Schmidt-Koenig and W. T. Keeton, eds. Springer-Verlag, Berlin.

25. Mrosovsky, N., and S. F. Kingsmill. 1985. How turtles find the sea. Z. Tierpsychol. 67: 237-265.

26. Mrosovsky, N. 1978. Orientation mechanisms of marine turtles. Pp. 413-419 in Animal Migration, Navigation, and IIoming, K. Schmidt-Koenig and W. T. Keeton, eds. Springer-Verlag, Berlin.

27. Batschelet, E. 1981. Circular Statistics in Biology. Academic Press, London. 